\title{
Motivation to Improve Mental Wellbeing via Community Physical Activity Initiatives and the Associated Impacts-A Cross-Sectional Survey of UK parkrun Participants
}

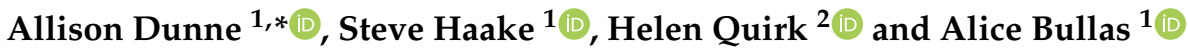 \\ 1 Advanced Wellbeing Research Centre, Sheffield Hallam University, Sheffield S9 3TU, UK; \\ s.j.haake@shu.ac.uk (S.H.); a.bullas@shu.ac.uk (A.B.) \\ 2 School of Health and Related Research, University of Sheffield, Sheffield S1 4DA, UK; h.quirk@sheffield.ac.uk \\ * Correspondence: a.r.dunne@shu.ac.uk
}

Citation: Dunne, A.; Haake, S.; Quirk, H.; Bullas, A. Motivation to Improve Mental Wellbeing via Community Physical Activity Initiatives and the Associated Impacts-A Cross-Sectional Survey of UK parkrun Participants. Int. J. Environ. Res. Public Health 2021, 18, 13072. https://doi.org/10.3390/ ijerph182413072

Academic Editors: Thomas E. Dorner and Igor Grabovac

Received: 29 October 2021

Accepted: 9 December 2021

Published: 11 December 2021

Publisher's Note: MDPI stays neutral with regard to jurisdictional claims in published maps and institutional affiliations.

Copyright: (c) 2021 by the authors. Licensee MDPI, Basel, Switzerland. This article is an open access article distributed under the terms and conditions of the Creative Commons Attribution (CC BY) license (https:// creativecommons.org/licenses/by/ $4.0 /)$.
Abstract: Participation in regular physical activity is a well-established strategy to support good mental wellbeing in adults with, and without, mental health conditions. The physical activity initiative parkrun is a free, weekly, timed, running and walking event which is attended by people from the local community of all abilities. The purpose of this study was to investigate the mental wellbeing of UK parkrun participants along with their motives for taking part and the impact of participation. Mental health conditions were self-reported in $2.5 \%$ of 60,000 respondents to an online survey of parkrunners, with the most prevalent being depression and anxiety. Those with mental health conditions were more motivated than those without to first participate in parkrun to manage their health conditions and improve their mental health. Those with mental health conditions were equally motivated to improve their physical health when compared to those without, and reported similar levels of improvement. Mental wellbeing scores for those with mental health conditions were close to the normal range, suggesting that engagement in parkrun may have had a role in limiting the effect of their illness. Community initiatives could replicate parkrun's model, and use the potential for both mental and physical health improvement, as well as health condition management, as a motivation for participation.

Keywords: mental health; mental wellbeing; physical activity; parkrun

\section{Introduction}

Good mental health and wellbeing are more than simply the absence of mental illness [1-3]: they have been described as a resource for everyday life [4]. The term mental wellbeing is often used interchangeably with positive mental health [5]. Subjective mental wellbeing relates to happiness, pleasure and life satisfaction along with personal growth and meaning in life [6]. Good mental wellbeing is a protective factor against developing future mental illness $[7,8]$ and can even prevent or delay some physical health conditions $[4,9]$.

Poor mental wellbeing can be a predictor of future chronic mental illness such as depression [10] and, to a lesser extent, anxiety disorders [11]. The World Health Organisation (WHO) report the prevalence of depression in the UK to be $4.5 \%$ and anxiety (including panic disorder and post-traumatic stress disorder (PTSD)) at 4.2\% [12].

The determinants of mental wellbeing, which should be included in any health promotion strategy, are social, cultural, environmental and biological [4,9]. Physical activity has been shown to enhance mental health and wellbeing [13-15]. Being active in a natural environment [16-18] and in a group [19] can further contribute to good mental wellbeing. Social prescribing is often used to connect people at risk of poor mental wellbeing with community initiatives available in their local area $[20,21]$ and an understanding of the 
motives of individuals to participate in physical activity may help with the selection and design of community initiatives [22].

\section{1. parkrun}

One community initiative which combines outdoor physical activity with social connectivity is parkrun (commonly written with a small ' $\mathrm{p}$ '). parkrun is a registered charity which supports free, weekly, timed, physical activity events in the UK and 22 other countries worldwide [23]. The participants run or walk a $5 \mathrm{~km}$ route in an outdoor setting on Saturday mornings, with a $2 \mathrm{~km}$ option in some locations for children aged 4-14 years on Sunday mornings [24]. Volunteers from the local community organise the events, with support and equipment provided by the parkrun charity headquarters [25]. Many of the runners and walkers occasionally volunteer to support the events by undertaking roles such as timekeeping and marshalling [25]. Since the first parkrun in the UK in 2004, the event has now been organised in nearly 2000 locations internationally, with up to ten new parkruns starting every week [26]. This study took place in 2018, just after the launch of the social prescribing scheme called parkrun practice, which is coordinated in conjunction with the Royal College of General Practitioners [27]. Thus, almost all participants in this study attended parkrun through self-motivation rather than by a formal referral from a healthcare professional.

\section{2. parkrun and Mental Wellbeing}

No studies of parkrun have used an internationally validated scale to measure mental wellbeing although a range of scales related to mental health and wellbeing have been utilised. The subjective mental wellbeing of UK parkrun participants was explored in a cross-sectional study by Stevinson and Hickson [28] using a five-point scale designed by the researchers themselves. The same scale was used in a later study by Hindley [29]. Both studies showed that parkrun attendance frequency was positively associated with high mental wellbeing scores, although these were not compared with results for the general population $[28,29]$. Two studies showed that Perceived Stress Scale scores were reduced after parkrun participation both immediately after the event [30] and in the year following the initial registration with parkrun [31]. Grunseit, Richards and Merom [32] investigated one aspect of mental wellbeing which they described as personal wellbeing (life satisfaction) for parkrunners in Australia. Their results suggest that women's personal wellbeing is connected to improved mental health, whereas men tended to experience wellbeing related to community connectedness. Stevinson and Hickson [31] used the Short Depression-Happiness Scale (SDHS) to measure the happiness and depression rating of parkrun participants, with improvements in mental health being maintained during the first year of parkrun participation.

\subsection{Aim of This Study}

There are no studies on parkrunners with mental health conditions compared to those without mental health conditions. In 2018, parkrun commissioned a survey to study the health and wellbeing of participants, including health conditions and mental wellbeing using the Short Warwick-Edinburgh Mental Wellbeing Scale (SWEMWBS) [33]. The aim of this study is to use the survey to compare the health and wellbeing of parkrunners with and without mental health conditions. The objectives are to determine the following:

1. What is their demographic?

2. What are their mental wellbeing scores?

3. What are their motives for first participating in parkrun as a runner or walker?

4. What are their perceived impacts of participation in parkrun as a runner or walker?

In answering these questions, this study seeks to provide guidance to those wishing to improve mental wellbeing using population-level physical activity initiatives. 


\section{Materials and Methods}

Ethical approval for the parkrun Health and Wellbeing Survey 2018 was granted by Sheffield Hallam University Research Ethics Committee on 24 July 2018 (reference number: ER7034346). This study was supported by the parkrun Research Board. The reporting of this manuscript adheres to established standards for reporting internet-based surveys using The Checklist for Reporting Results of Internet E-Surveys (CHERRIES) [34].

\subsection{Data Collection}

\subsubsection{Inclusion and Exclusion Criteria}

All UK parkrun registrants aged 16 and over (at the time of the survey) were invited to complete the online questionnaire. There was no paper version available. The survey was only available in the English language; there were no other explicit exclusion criteria.

\subsubsection{The Survey}

This study used a cross-sectional online survey (the parkrun Health and Wellbeing Survey 2018). A power calculation was carried out prior to the survey which suggested that the sub-groups to be analysed would need to have $>1000$ participants if a moderate effect size was to be found with a significance of $p<0.05$. A pilot study of 200 participants suggested a sample size of approximately 100,000 responses to get this fidelity. The survey was sent between 29 October 2018 and 3rd December 2018 to all adults in the UK aged 16 and over who were registered with parkrun; approximately two-thirds of these were active parkrun participants.

Data were collected using Qualtrics software (www.qualtrics.com, accessed on 29 October 2021). The full survey details and methods are described in earlier publications [35,36]. During the survey, respondents recorded their unique parkrun identification number which was used to match the survey responses with (1) demographic information (gender, date of birth and Index of Multiple Deprivation (IMD) from the postcode provided at registration) and (2) parkrun participation information (the date of registration with parkrun and the number of completed events). At the time of parkrun registration, the registrants were asked about their prior levels of physical activity. This was also matched to their survey responses.

The survey asked 47 questions relating to various aspects of mental and physical health and wellbeing. Responses to the following questions were used in this study:

- $\quad$ arkrun participation type: The parkrun model allows runners and walkers to volunteer at events if they wish to. It is also possible to volunteer without ever running or walking at the event. The participants were asked to tick the option that best described their participation in parkrun. Options were (1) volunteer, (2) runner/walker who volunteers and (3) runner/walker (who does not volunteer). This study does not include the data from those who only volunteer (option 1).

- Health condition, illness or disability: participants were asked "Are your day-to-day activities limited because of a health condition or disability which has lasted, or is expected to last, at least 12 months? Include conditions related to old age, sensory deficits, mobility problems, developmental conditions, learning impairments and mental health." The possible responses were; Yes, limited a lot, Yes, limited a little, No, Do not know or would rather not say. Participants who indicated that they did have a health condition, illness or disability were then asked to select all the applicable conditions from a list of 56 options. A further option for Other was also available with a free text response (not included here)

- Motives for running or walking at parkrun: participants were asked, "What motivated you to first participate at parkrun as a runner or walker?" [they were asked to select a maximum of three answers out of a possible 20 motives]. Additionally, the choice Other allowed a free-text response (not reported here). The answer choices were displayed in randomised order to help reduce response bias. 
- $\quad$ SWEMWBS: Mental wellbeing was measured using seven SWEMWBS statements introduced with "Below are some statements about feelings and thoughts. Please tick the box that describes your experience of each over the last 2 weeks". The participant could choose from; None of the time, Rarely, Some of the time, Often, All of the time. Participants who responded to all seven statements were given a SWEMWBS score [33]. The validity and reliability of the SWEMWBS tool has been tested in English-speaking clinical and non-clinical adult populations in the UK $[33,37,38]$ and clinical populations in Singapore [39].

- Perceived impact of running or walking at parkrun: participants were asked, "Thinking about the impact of parkrun on your health and wellbeing, to what extent has running or walking at parkrun changed:" [list of 15 impacts: much worse/worse/no im$\mathrm{pact} / \mathrm{better} / \mathrm{much}$ better]. Additionally, the choice Other allowed a free-text response (not used here). The answer choices were randomised to help reduce response bias. Survey respondents who earlier indicated they had a health condition, disability or illness were asked one additional question to indicate the impact of running and walking on managing their health condition, disability or illness (much worse/worse/no impact/better/much better).

For the purposes of this report mental health conditions are defined as including the following conditions: depression, anxiety, panic attacks, post-traumatic stress disorder (PTSD), bipolar, attention deficit hyperactivity disorder (ADHD), schizophrenia and dementia (including Alzheimer's disease) but excluding developmental disorders, organic mental disorders and neurological disorders.

\subsection{Statistics}

\subsubsection{Preliminary Analysis}

The dataset of 60,000 respondents contained 38,072 runners/walkers and 21,928 runners/walkers who also volunteered. Data validation and preparation for statistical analysis were completed using Excel for PC (V16, Microsoft Corporation) and the initial handling and validation of raw data from the survey are described in a previous publication [36].

Some survey respondents did not answer all the questions on the survey or during parkrun registration; data tables include the relevant sample size $(n)$ to reflect this.

\subsubsection{Statistical Analysis}

Statistical analysis was used to compare demographic data for the respondents who reported mental health conditions with those who did not. As the conditions for parametric statistical methods were not met (not all results showed a normal distribution and there is no meaningful zero for the SWEMWBS) the data analysis was conducted using nonparametric statistical tools and reporting methods. SWEMWBS results were compared using Mann-Whitney $\mathrm{U}$ tests with effect size calculated using $r=Z / \sqrt{ } n$, where $Z$ is the standardised test statistic and $n$ the number of ranked respondents [40]. The $\chi^{2}$ statistic was used to evaluate the differences between the motives for, and impacts of, parkrun participation between those who did and did not report mental health conditions. Effect size was calculated using $\varphi_{c}=\sqrt{ }\left(\chi^{2} / n(k-1)\right.$ where $\chi^{2}$ is the test statistic, $n$ is the number of respondents and $k$ is the number of rows or columns (whichever is the smaller). As commonly used, an effect size $=0.1$ was considered small, 0.3 medium, and 0.5 large [41] . Cross tabulation and statistical analysis were carried out using IBM SPSS Statistics for PC (v26). Statistical significance was set at $p<0.001$.

\section{Results}

\subsection{Demographics of Participants}

Table 1 shows that 1496 participants reported a mental health condition; this represented $2.5 \%$ of the sample. It can be seen that $51.7 \%$ of the full sample were female, $9.6 \%$ came from the most deprived neighbourhoods and $5.1 \%$ reported less than one period of 
physical activity of $30 \mathrm{~min}$ or more per week at the time of parkrun registration (i.e., they were classed as inactive).

Those with a mental health condition were on average 4 years younger than those without ( 45.0 vs. 49.0 years), had been registered for a shorter amount of time ( $2.2 \mathrm{vs}$. 2.6 years), had done fewer parkruns in total (median number of runs 7 vs. 10 ), and had done fewer parkruns per year (12.6 vs. 14.5). All effect sizes were small.

Table 1. Demographics for the Health and Wellbeing Survey respondents at the time of the survey distribution (29th October to 3rd December 2018).

\begin{tabular}{|c|c|c|c|c|c|c|}
\hline & $\begin{array}{l}\text { Full } \\
\text { Sample }\end{array}$ & $\begin{array}{l}\text { With a Mental } \\
\text { Health } \\
\text { Condition }\end{array}$ & $\begin{array}{l}\text { Without a Mental } \\
\text { Health } \\
\text { Condition }\end{array}$ & $x^{2}$ & $p$ & $\varphi_{c}$ \\
\hline$n$ & 60,000 & 1496 & 58,504 & & & \\
\hline Gender $n$ & 47,676 & 1170 & 46,506 & 90.9 & $<0.001$ & 0.04 \\
\hline Female & $51.7 \%$ & $53.5 \%$ & $51.7 \%$ & & & \\
\hline Male & $48.3 \%$ & $46.5 \%$ & $48.3 \%$ & & & \\
\hline Index of Multiple Deprivation $n$ & 46,131 & 1127 & 45,004 & 0.48 & 0.924 & 0.003 \\
\hline Quartile 1 & $9.6 \%$ & $9.1 \%$ & $9.6 \%$ & & & \\
\hline Quartile 2 & $20.4 \%$ & $21.0 \%$ & $20.3 \%$ & & & \\
\hline Quartile 3 & $30.1 \%$ & $29.9 \%$ & $30.1 \%$ & & & \\
\hline Quartile 4 & $40.0 \%$ & $39.9 \%$ & $40.0 \%$ & & & \\
\hline $\begin{array}{l}\text { Activity level at parkrun registration } \\
n\end{array}$ & 43,475 & 1069 & 42,406 & 3.65 & 0.456 & 0.009 \\
\hline$<1$ & $5.1 \%$ & $5.6 \%$ & $5.1 \%$ & & & \\
\hline$\approx 1$ & $11.5 \%$ & $13.1 \%$ & $11.5 \%$ & & & \\
\hline$\approx 2$ & $22.7 \%$ & $22.2 \%$ & $22.7 \%$ & & & \\
\hline$\approx 3$ & $33.7 \%$ & $32.4 \%$ & $33.8 \%$ & & & \\
\hline \multirow[t]{2}{*}{$\geq 4$} & $26.9 \%$ & $26.8 \%$ & $26.9 \%$ & & & \\
\hline & Full sample & $\begin{array}{l}\text { With mental health } \\
\text { condition }\end{array}$ & $\begin{array}{l}\text { Without mental } \\
\text { health condition }\end{array}$ & Z & $p$ & Effect size \\
\hline Age $n$ & 43,621 & 1069 & 42,552 & & & \\
\hline Median & 48.91 & 44.96 & 49.02 & 11.9 & $<0.001$ & 0.06 \\
\hline Range: minimum to maximum & $16.0-93.5$ & $16.2-84.5$ & $16.0-93.5$ & & & \\
\hline Years registered $n$ & 60,000 & 1496 & 58,504 & & & \\
\hline Median & 2.6 & 2.2 & 2.6 & 4.59 & $<0.001$ & 0.02 \\
\hline Range: minimum to maximum & $0-14.1$ & $0-13.3$ & $0-14.1$ & & & \\
\hline Number of parkruns completed $n$ & 60,000 & 1496 & 58,504 & & & \\
\hline Median & 10 & 7 & 10 & 5.65 & $<0.001$ & 0.02 \\
\hline Range: minimum to maximum & $0-612$ & $0-612$ & $0-582$ & & & \\
\hline Number of parkruns per year $n$ & 34,609 & 841 & 33,768 & & & \\
\hline Median & 14.4 & 12.6 & 14.5 & 4.86 & $<0.001$ & 0.03 \\
\hline Range: minimum to maximum & 0 to 55.6 & 0 to 50.3 & 0 to 55.6 & & & \\
\hline
\end{tabular}

Figure 1 shows the mental health conditions reported by the respondents. Depression and anxiety were the most common mental health conditions reported by $1120(1.9 \%)$ and $834(1.4 \%)$ respondents, respectively. Some respondents reported more than one mental health condition with the maximum number of mental health conditions reported being six (Supplementary Material). A matrix showing the number of respondents with each condition is shown in Table 2. For those with depression, 584 (52\%) also had anxiety, 184 $(16 \%)$ had panic attacks and $89(8 \%)$ had PTSD. Of the 834 with anxiety, $178(21 \%)$ had panic attacks and $69(8 \%)$ had PTSD. 


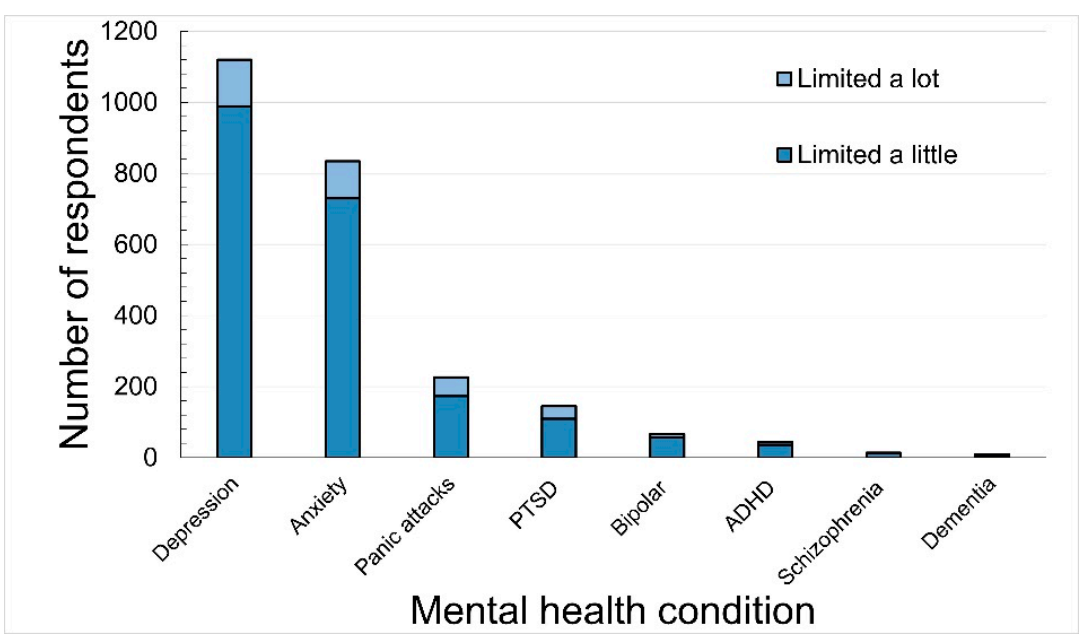

Figure 1. Number of respondents who selected specific mental health conditions $(n=1496)$. Note: dementia includes Alzheimer's disease.

Table 2. Matrix showing the number of respondents who reported one or two mental health conditions. Note: dementia includes those reporting Alzheimer's disease. The coloured cells show the number of people with a single health condition.

\begin{tabular}{ccccccccc}
\hline $\begin{array}{c}\text { Limited Little and } \\
\text { a Lot Combined }\end{array}$ & Depression & Anxiety & $\begin{array}{c}\text { Panic } \\
\text { Attacks }\end{array}$ & PTSD & Bipolar & ADHD & Schizophrenia & Dementia \\
\hline Depression & 1120 & 584 & 184 & 89 & 28 & 26 & 7 & 0 \\
Anxiety & & 834 & 178 & 69 & 27 & 25 & 5 & 0 \\
Panic attacks & & & 226 & 2 & 8 & 5 & 2 & 0 \\
PTSD & & & 145 & 3 & 2 & 2 & 1 \\
Bipolar & & & & 67 & 2 & 0 \\
ADHD & & & & & 44 & 0 \\
Schizophrenia & & & & & & & \\
Dementia & & & & & & & \\
\hline
\end{tabular}

\subsection{Short Warwick-Edinburgh Mental Wellbeing Scores}

Table 3 shows SWEMWBS scores for those with and without mental health conditions and who participated in parkrun as a runner/walker. The two largest conditions reported (by respondents who completed the SWEMWBS) were depression $(n=1040)$ and anxiety ( $n=776$ ) with scores of 19.3 compared to 25.0 for those without the conditions; these were significantly different but with small effect sizes of 0.16 and 0.14 , respectively. Those with mental health conditions had a lower wellbeing score than those without for six of the conditions listed with the lowest score of 18.6 for those with panic attacks and PTSD compared to 25.0 for those without; there were small effect sizes of 0.06 and 0.08 , respectively.

\subsection{Motives for First Participating in parkrun for Those with a Mental Health Condition}

The motives for first participating in parkrun as a runner or walker are shown in Table 4 . The most reported motive for those with a mental health condition was to improve my mental health; the proportion choosing this motive was significantly larger for those with a mental health condition than for those without $(49.0 \%$ vs. $12.0 \%$; small effect size $=0.17)$. Similarly, those with a mental health condition were more likely than those without to choose to improve my happiness $(10.8 \%$ vs. $6.6 \%$; moderate effect size $=0.26)$ and to improve or manage my health condition, disability or illness $(16.8 \%$ vs. $3.0 \%$; small effect size $=0.12)$. 
Table 3. Short Warwick-Edinburgh Mental Wellbeing Scale scores for those with and without specific mental health conditions who participated in parkrun as a runner/walker: statistical comparison used the Mann-Whitney U test.

\begin{tabular}{|c|c|c|c|c|c|c|c|c|c|}
\hline \multirow[b]{2}{*}{ Condition } & \multicolumn{2}{|c|}{ Full Sample } & \multicolumn{2}{|c|}{ With Condition } & \multicolumn{2}{|c|}{ Without Condition } & \multirow[b]{2}{*}{$Z$} & \multirow[b]{2}{*}{$p$} & \multirow[b]{2}{*}{$r$} \\
\hline & $n$ & Median & $n$ & Median & $n$ & Median & & & \\
\hline Depression & 56,341 & 25.03 & 1040 & 19.25 & 55,301 & 25.03 & 39.0 & $<0.001$ & 0.16 \\
\hline Anxiety & 56,341 & 25.03 & 776 & 19.25 & 55,565 & 25.03 & 33.1 & $<0.001$ & 0.14 \\
\hline Panic attacks & 56,341 & 25.03 & 206 & 18.59 & 56,135 & 25.03 & 19.3 & $<0.001$ & 0.08 \\
\hline PTSD & 56,341 & 25.03 & 136 & 18.59 & 56,205 & 25.03 & 14.9 & $<0.001$ & 0.06 \\
\hline Bipolar & 56,341 & 25.03 & 60 & 18.92 & 56,281 & 25.03 & 9.23 & $<0.001$ & 0.04 \\
\hline ADHD & 56,341 & 25.03 & 39 & 19.25 & 56,302 & 25.03 & 6.88 & $<0.001$ & 0.03 \\
\hline Schizophrenia & 56,341 & 25.03 & 12 & 20.80 & 56,329 & 25.03 & 3.46 & 0.001 & 0.01 \\
\hline Dementia/Alzheimer's disease & 56,341 & 25.03 & 7 & 24.11 & 56,334 & 25.03 & 1.34 & 0.182 & 0.01 \\
\hline All & 56,341 & 25.03 & 1389 & 19.25 & 54,952 & 25.03 & 43.1 & $<0.001$ & 0.17 \\
\hline
\end{tabular}

Table 4. Response to the question "What motivated you to first participate at parkrun as a runner or walker?" Participants $(n=59,243)$ were able to select up to three motives.

\begin{tabular}{|c|c|c|c|c|c|c|}
\hline & $\begin{array}{c}\text { Full Sample } \\
n=59,282\end{array}$ & $\begin{array}{c}\text { With } \\
\text { a Mental Health } \\
\text { Condition } \\
n=1496\end{array}$ & $\begin{array}{c}\text { Without } \\
\text { a Mental Health } \\
\text { Condition } \\
n=57,786\end{array}$ & & & \\
\hline Motive & $\%$ & $\%$ & $\%$ & $\chi^{2}$ & $p$ & $\varphi_{c}$ \\
\hline To contribute to my fitness & $56.2 \%$ & $36.4 \%$ & $56.7 \%$ & 239.4 & $<0.001$ & 0.06 \\
\hline To improve my physical health & $37.0 \%$ & $38.1 \%$ & $37.0 \%$ & 0.47 & 0.381 & 0.00 \\
\hline $\begin{array}{c}\text { To gain a sense of personal } \\
\text { achievement }\end{array}$ & $26.9 \%$ & $23.6 \%$ & $26.9 \%$ & 7.96 & 0.005 & 0.01 \\
\hline To get a recorded time for a $5 \mathrm{k}$ & $21.4 \%$ & $12.6 \%$ & $21.6 \%$ & 69.1 & $<0.001$ & 0.03 \\
\hline To manage my weight & $19.8 \%$ & $22.6 \%$ & $19.7 \%$ & 7.68 & 0.006 & 0.01 \\
\hline $\begin{array}{l}\text { My friends, family or colleagues } \\
\text { encouraged me to }\end{array}$ & $15.2 \%$ & $13.3 \%$ & $15.2 \%$ & 4.13 & 0.042 & 0.01 \\
\hline To train for another sport/event & $14.2 \%$ & $9.1 \%$ & $14.3 \%$ & 32.3 & $<0.001$ & 0.02 \\
\hline To improve my mental health & $13.0 \%$ & $49.0 \%$ & $12.0 \%$ & 1742.2 & $<0.001$ & 0.17 \\
\hline To feel part of a community & $11.0 \%$ & $9.8 \%$ & $11.0 \%$ & 2.41 & 0.121 & 0.01 \\
\hline To spend time outdoors & $10.3 \%$ & $8.3 \%$ & $10.4 \%$ & 6.49 & 0.011 & 0.01 \\
\hline To compete with others & $9.8 \%$ & $4.3 \%$ & $9.9 \%$ & 52.1 & $<0.001$ & 0.03 \\
\hline To spend time with friends & $7.7 \%$ & $4.3 \%$ & $7.8 \%$ & 24.6 & $<0.001$ & 0.02 \\
\hline To spend time with family & $7.3 \%$ & $3.8 \%$ & $7.4 \%$ & 27.2 & $<0.001$ & 0.02 \\
\hline To improve happiness & $6.7 \%$ & $10.8 \%$ & $6.6 \%$ & 40.5 & $<0.001$ & 0.26 \\
\hline $\begin{array}{l}\text { It was part of a 'couch to } 5 \mathrm{~K}^{\prime} \\
\text { programme }\end{array}$ & $5.3 \%$ & $6.0 \%$ & $5.3 \%$ & 1.41 & 0.236 & 0.01 \\
\hline To meet new people & $4.1 \%$ & $4.9 \%$ & $4.1 \%$ & 2.46 & 0.117 & 0.01 \\
\hline To be active in a safe environment & $4.1 \%$ & $5.6 \%$ & $4.0 \%$ & 9.21 & 0.002 & 0.01 \\
\hline $\begin{array}{l}\text { To improve or manage my health } \\
\text { condition, disability or illness }\end{array}$ & $3.4 \%$ & $16.8 \%$ & $3.0 \%$ & 836.3 & $<0.001$ & 0.12 \\
\hline To raise money for charity & $0.5 \%$ & $0.5 \%$ & $0.5 \%$ & 0.00 & 0.980 & 0.00 \\
\hline A health professional advised me to & $0.3 \%$ & $1.3 \%$ & $0.3 \%$ & 48.8 & $<0.001$ & 0.03 \\
\hline
\end{tabular}

For the full sample, the top five motives were to contribute to my fitness $(56.2 \%)$, to improve my physical health (37.0\%), to gain a sense of personal achievement $(26.9 \%)$, to get a recorded time for a $5 k(21.4 \%)$ and to manage my weight $(19.8 \%)$. Those with a mental health condition were less likely than those without a health condition to choose to contribute to my fitness (36.4\% vs. $56.7 \%$ ) and to get a recorded time for a $5 k$ (12.6\% vs. $21.6 \%)$, although effect sizes were small (less than 0.10 ); there was no significant difference for the three remaining top five motives. 


\subsection{Perceived Impact of Running or Walking at parkrun}

Table 5 shows the perceived impact of running or walking at parkrun for those with and without a mental health condition with the proportions for better and much better combined. The remaining proportion for each measure was primarily no impact with the combined proportions for much worse and worse typically less than $1 \%$. Seven of the measures showed statistical differences between those with and without a mental health condition $(p<0.001)$ with the largest difference seen for improvements to mental health $(82.1 \%$ vs. $68.9 \%$ : small effect size $=0.05)$.

Table 5. Response to the question "Thinking about the impact of parkrun on your health and wellbeing, to what extent has running or walking at parkrun changed your/the ... " Proportions are for those reporting better and much better; comparison using $X^{2}$ tests.

\begin{tabular}{|c|c|c|c|c|c|c|c|c|c|}
\hline \multirow[b]{2}{*}{$\begin{array}{l}\text { Impact of Running or Walking } \\
\text { at parkrun }\end{array}$} & \multicolumn{2}{|c|}{ Full Sample } & \multicolumn{2}{|c|}{$\begin{array}{l}\text { With a } \\
\text { Mental Health } \\
\text { Condition }\end{array}$} & \multicolumn{2}{|c|}{$\begin{array}{l}\text { Without a Mental } \\
\text { Health Condition }\end{array}$} & \multirow[b]{2}{*}{$\chi^{2}$} & \multirow[b]{2}{*}{$p$} & \multirow[b]{2}{*}{$\varphi_{c}$} \\
\hline & $n$ & $\begin{array}{l}\text { Better and } \\
\text { Much Better }\end{array}$ & $n$ & $\begin{array}{l}\text { Better and } \\
\text { Much Better }\end{array}$ & $n$ & $\begin{array}{l}\text { Better and } \\
\text { Much Better }\end{array}$ & & & \\
\hline Sense of personal achievement & 56,282 & $90.7 \%$ & 1385 & $87.2 \%$ & 54,890 & $90.8 \%$ & 21.3 & $<0.001$ & 0.02 \\
\hline Fitness & 56,293 & $89.3 \%$ & 1386 & $87.9 \%$ & 54,868 & $89.4 \%$ & 3.18 & 0.075 & 0.01 \\
\hline Physical health & 56,241 & $84.7 \%$ & 1388 & $83.4 \%$ & 54,874 & $84.7 \%$ & 1.68 & 0.195 & 0.01 \\
\hline Happiness & 56,203 & $78.8 \%$ & 1389 & $78.2 \%$ & 54,825 & $78.8 \%$ & 0.30 & 0.583 & 0.00 \\
\hline Amount of time spend outdoors & 56,251 & $74.1 \%$ & 1387 & $78.1 \%$ & 54,864 & $74.0 \%$ & 12.1 & 0.001 & 0.02 \\
\hline Enjoyment of competing & 56,243 & $72.7 \%$ & 1385 & $60.0 \%$ & 54,874 & $73.0 \%$ & 113.3 & $<0.001$ & 0.05 \\
\hline How much you feel part of community & 56,185 & $69.7 \%$ & 1383 & $64.5 \%$ & 54,827 & $69.8 \%$ & 17.5 & $<0.001$ & 0.02 \\
\hline Mental health & 56,175 & $69.3 \%$ & 1387 & $82.1 \%$ & 54,848 & $68.9 \%$ & 110.6 & $<0.001$ & 0.04 \\
\hline Confidence & 56,253 & $61.3 \%$ & 1383 & $68.1 \%$ & 54,806 & $61.2 \%$ & 27.5 & $<0.001$ & 0.02 \\
\hline Ability to be active in safe environment & 56,224 & $59.9 \%$ & 1388 & $68.9 \%$ & 54,811 & $59.7 \%$ & 47.4 & $<0.001$ & 0.03 \\
\hline Number of new people you meet & 56,247 & $57.5 \%$ & 1386 & $57.0 \%$ & 54,873 & $57.5 \%$ & 0.18 & 0.673 & 0.00 \\
\hline Ability to control weight & 56,218 & $52.3 \%$ & 1382 & $50.0 \%$ & 54,792 & $52.4 \%$ & 3.13 & 0.077 & 0.01 \\
\hline $\begin{array}{c}\text { Overall lifestyle choices (e.g., diet and } \\
\text { smoking) }\end{array}$ & 56,160 & $51.8 \%$ & 1387 & $56.4 \%$ & 54,862 & $51.6 \%$ & 12.4 & $<0.001$ & 0.02 \\
\hline Amount of time you spend with friends & 6202 & $41.1 \%$ & 1389 & $42.9 \%$ & 54,752 & $41.1 \%$ & 1.96 & 0.162 & 0.01 \\
\hline Amount of time you spend with family & 56,235 & $27.7 \%$ & 1385 & $24.4 \%$ & 54,817 & $27.8 \%$ & 7.91 & 0.005 & 0.01 \\
\hline $\begin{array}{l}\text { * Ability to manage your health } \\
\text { condition, disability or illness }\end{array}$ & 5351 & $65.5 \%$ & 1395 & $75.8 \%$ & 3956 & $61.8 \%$ & 88.65 & $<0.001$ & 0.13 \\
\hline
\end{tabular}

* response only for those with health conditions.

The largest proportion reporting improvement for the full sample was for $a$ sense of personal achievement; a smaller proportion of those with a mental health condition reported improvement compared to those without $(87.2 \%$ vs. $90.8 \%$ : small effect size $=0.02)$. The next most improved measures were fitness $(89.3 \%)$, physical health $(84.7 \%)$, happiness $(78.8 \%)$ and the amount of time spent outdoors ( $74.1 \%)$; there were no significant differences between those with and without a mental health condition.

A larger proportion of those with a mental health condition reported improvements compared to those without for confidence $(68.1 \%$ vs. $61.2 \%$ : small effect size $=0.02)$, the ability to be active in a safe environment ( $68.9 \%$ vs. $59.7 \%$; small effect size $=0.03)$ and overall lifestyle choices $(56.4 \%$ vs. $51.6 \%$ : small effect size $=0.02)$. A smaller proportion of those with a mental health condition reported improvements compared to those without to the enjoyment of competing $(60.0 \%$ vs. $73.0 \%$; small effect size $=0.04)$ and how much you feel part of a community ( $64.5 \%$ vs. $69.8 \%$ : small effect size $=0.02)$.

The final question in the series of impact questions was only asked to those who had indicated that they had a health condition. Respondents with mental health conditions were significantly more likely than those without mental health conditions to report improvements in their ability to manage the health condition since participating in parkrun ( $75.8 \%$ compared to $61.8 \%$; small effect size $=0.13$ ). The question did not specify the health 
condition so responses may have referred to non-mental health conditions (e.g., arthritis, asthma, and cancer).

\subsection{Note on Results Section}

The original data analysis segmented the results into age categories, gender, Index of Multiple Deprivation and activity level prior to parkrun participation. When the groups with and without mental health conditions were compared there were no significant findings within the segmented groups, so for clarity of reading we did not report each category here.

\section{Discussion}

In this self-selected sample of UK parkrun participants, $2.5 \%$ of respondents had a mental health condition: this was a lower prevalence of depression and anxiety than the published rates for the general population of the UK [12]. Those with a mental health condition were more likely to be female than male in a ratio 1.15:1 and more likely to be inactive at parkrun registration compared to those without mental health conditions. Those with a mental health condition tended to be younger, less likely to live in a deprived neighbourhood and did fewer parkruns per year than those without a condition. They were motivated to first participate in parkrun to manage their health conditions and improve their mental health and happiness; they perceived greater impact of parkrun for the first two of these motives.

Those with a mental health condition were less motivated to first participate in parkrun to improve their fitness although large proportions reported improvements to both this and their physical health that they attributed to parkrun participation. While those with a mental health condition were less motivated by competition, training for another event or getting a recorded time for a $5 \mathrm{k}, 60 \%$ reported their enjoyment of competition to be improved since participating in parkrun (although this was still smaller than the $73 \%$ for those without a mental health condition). There were also large proportions reporting improvement to the measures relating to the supportive factors for good mental wellbeing such as spending time outdoors, being active in a safe environment and confidence. An understanding of the different motivations of people with and without mental health conditions to take part in physical activity will allow the developers of new community physical activity initiatives to support the engagement of both groups. Scales such as the Physical Activity and Leisure Motivation Scale (PALMS) [22] could be used in future research to develop a deeper understanding of the motivations of people with mental health conditions to participate in physical activity.

Mental wellbeing scores for the survey respondents showed some findings of note. The median SWEMWBS score for all survey respondents was 25.0. This is higher than the mean score for England (23.7 and 23.2 for males and females [42]) and the difference might be considered clinically significant [33]. At the time of the survey, those with a mental health condition reported SWEMWBS scores 5.8 to 6.4 points lower than those without a mental health condition. A low SWEMWBS score (20 and below) can be indicative of poor mental wellbeing; the survey respondents with mental health conditions had scores just below this threshold [43]. Given the perceived improvements by those with a mental health condition, particularly to measures related mental health, it is possible that without participation in parkrun, they may have experienced a deterioration of their mental wellbeing, putting them at greater risk of symptomatic mental illness.

Those with mental health conditions were equally motivated by physical health as those without and similarly large proportions (over 8 out of 10 respondents) report improvements to it that they attributed to parkrun. This is important since people with mental health conditions are at risk of physical comorbidities such as cardiovascular disease, type II diabetes mellitus and physical health conditions related to obesity [44,45]. 


\subsection{Clinical Implications}

People with symptomatic mental health conditions such as depression and anxiety often have low energy and motivation levels [12] and therefore may be less likely to attend organised physical activity events than those without mental health conditions [46]. It is also common for people with mental health conditions to experience social exclusion [47]. From previous research, it appears that parkrun is one possible activity to overcome these challenges and is a supportive activity for people with mental health difficulties [48]. The findings here further support this concept as the motivation to attend parkrun by people with mental health conditions as a way of managing their health conditions was high. The results suggest that parkrun is an acceptable option for health care practitioners to recommend via social prescription for mental health condition management. For the majority of the group with mental health conditions the initial motivation was not to improve physical health and fitness so this came as an added bonus shown through the impact results. People with mental health conditions often have poor physical health [4], so an intervention which can improve physical health while supporting mental wellbeing is an appropriate offering for social prescribers.

\subsection{Comparison with Published Studies}

This study used a validated mental wellbeing scale to support previous research which used other methods to describe the mental wellbeing of parkrun participants $[28,29,32]$. The body of research (including the results presented here) suggests that parkrun attendance can support good mental wellbeing in parkrun participants without mental health conditions. This study expands this concept to include those people with mental health conditions. Both groups reported different motivations to participate in parkrun; a finding which could be explored further when planning how to support people with differing mental health needs to engage with parkrun.

\subsection{Implications for parkrun and Other Population-Level Events}

The findings demonstrate that participation in parkrun could have a potentially important role in the management of mental health conditions. The evidence suggests that parkrun is perceived by those reporting mental health conditions to improve their mental wellbeing as well as physical health and fitness. Given the two-way relationship between physical and mental health this is an important finding [49]. These results would suggest that initiatives like parkrun could be used to help encourage people living with mental health conditions to increase their activity levels, spend time with others and increase the amount of time spent in the outdoors-all shown to contribute to good mental wellbeing. There is an opportunity here for initiatives such as parkrun to continue to support those with poor mental wellbeing and those living with mental health conditions to participate (e.g., through initiatives such as the parkrun PROVE project [50]). A social prescribing scheme such as the parkrun practice initiative [51] is another route for parkrun to engage with people with mental health conditions. Stevinson [52] suggested that the characteristics that made parkrun attractive to participants were that it was free, regular, can encourage socialisation and takes place in the outdoors. As well as these characteristics, the findings of this study suggest that the promotion or prescription of initiatives like parkrun should emphasise the potential benefits to mental health (as well as physical health), general wellbeing and the ability to manage health condition(s).

\subsection{Limitations}

While this study has the advantage of the use of a validated mental wellbeing scale in a large cohort, there are several potential limitations. The online data collection for the parkrun Health and Wellbeing Survey produced 60,000 fully completed surveys. This was lower than the planned sample size of 100,000, estimated following the pilot study. However, this was considered during segmentation of the sample to allow completion of a satisfactory statistical analysis. The cohort who completed the survey were older, more 
active, less likely to live in an area of deprivation and had completed more parkrun events per year than the whole parkrun population. The results of this analysis cannot necessarily be extrapolated to make claims about the complete parkrun population. The secondary data analysis uses a cross-sectional approach which does not allow for capture of baseline mental wellbeing scores. The question about motivation to participate in parkrun was asked retrospectively at the time of the survey; a more insightful method could be to ask the participants their motivation at the time of parkrun registration. The survey respondents self-reported their mental health conditions; these may not have been formally diagnosed in every case. The question about health conditions only collected information about conditions that limit daily activities and were long lasting. Information about previously diagnosed, but now well-controlled, mental health conditions was not collected. It should also be considered that maybe only those people in the local community with well-managed mental health conditions were able to participate in parkrun and/or take part in the survey.

\section{Conclusions}

Mental health conditions were prevalent in $2.5 \%$ of 60,000 respondents to a survey of parkrunners, with the most prevalent being depression, anxiety, panic attacks and PTSD, often in combination. Those with mental health conditions tended to be younger and had participated in parkrun marginally less than those without. They were more motivated than those without mental health conditions to first participate in parkrun to improve their mental health and manage their health conditions; a larger proportion reported improvements to both. Those with mental health conditions were equally motivated to improve their physical health, weight management and fitness when compared to those without and showed similar levels of improvement. They were less motivated by competition, although $60 \%$ said their enjoyment of this was improved.

The mental wellbeing scores at the survey for those with mental health conditions were close to the normal range, suggesting that engagement in parkrun may have had a role in limiting the effect of their illness. This is an area which warrants further exploration. The characteristics of parkrun that make it a suitable social prescribing offer are that it is free, regular, can encourage socialisation and takes place in the outdoors. If other events want to support those with mental health conditions, they can replicate this model and both they and parkrun should emphasise both the mental and physical improvements that could be gained.

Supplementary Materials: The following are available online at https://www.mdpi.com/article/ 10.3390/ijerph182413072/s1. Table S1: Responses to the question "What is your health condition, disability or illness? Please select all that apply".

Author Contributions: Conceptualisation, S.H. (with Chrissie Wellington at parkrun). Methodology, S.H., H.Q. and A.B. Software, S.H. and A.B. Validation, A.B., S.H. and A.D. Formal analysis, S.H. and A.D. Investigation, S.H., A.D. and H.Q. Resources, S.H. Data curation, S.H. and A.D. Writingoriginal draft preparation, A.D. Writing—review and editing, S.H., H.Q. and A.D. Visualisation, A.D. and S.H. Supervision, S.H., H.Q. and A.B. Project administration, S.H. Funding acquisition, S.H. All authors have read and agreed to the published version of the manuscript.

Funding: parkrun commissioned Sheffield Hallam University (A.B., H.Q. and S.H.) to conduct the original survey. For the preparation of the manuscript, H.Q. was funded by the National Institute for Health Research (NIHR) School for Public Health Research (SPHR) post-doctoral launching fellowship. A.D. was self-funded and S.H. was funded by Sheffield Hallam University.

Institutional Review Board Statement: Ethical approval for the parkrun Health and Wellbeing study was granted by Sheffield Hallam University Research Ethics Committee on 24 July 2018 (reference number: ER7034346).

Informed Consent Statement: Informed consent was obtained from all subjects involved in this study.

Data Availability Statement: The datasets supporting the conclusions of this article are stored in the Sheffield Hallam University Research Database (SHURDA) for access and in accordance with the 
Data Protection Act 2018 and the General Data Protection Regulation 2018. In the hope of ensuring the full research potential of the dataset, a copy of the anonymised data will be accessible to researchers for research purposes through the parkrun Research Board, as originally outlined in the participant information sheet.

Acknowledgments: The authors would like to thank all the parkrun participants who completed the survey and to thank the parkrun Research Board for their support and guidance; in particular Mike. Graney for parkrun data acquisition and Chrissie Wellington for her contribution to the conception of the parkrun Health and Wellbeing Survey.

Conflicts of Interest: S.H. is chair, A.B. and H.Q are deputy chairs, of the parkrun research board. A.D. is a parkrun participant. None of the authors completed the survey.

\section{References}

1. Keyes, C. Mental Illness and/or Mental Health? Investigating Axioms of the Complete State Model of Health. J. Consult. Clin. Psychol. 2005, 73, 539-548. [CrossRef]

2. OECD/EU. Health at a Glance Europe 2018: State of Health in the EU Cycle; OECD Publishing: Paris, France, 2018.

3. Vaillant, G.E. Mental Health. Am. J. Psychiatry 2003, 160, 1373-1384. [CrossRef]

4. Barry, M.M.; Clarke, A.M.; Petersen, I.; Jenkins, R. Implementing Mental Health Promotion, 2nd ed.; Springer: Cham, Switzerland, 2019.

5. Tennant, R.; Hiller, L.; Fishwick, R.; Platt, S.; Joseph, S.; Weich, S.; Parkinson, J.; Secker, J.; Stewart-Brown, S. The Warwick-Edinburgh Mental Well-being Scale (WEMWBS): Development and UK validation. Health Qual. Life Outcomes 2007, 5, 63. [CrossRef]

6. Diener, E.; Lucas, R.E.; Oishi, S. Advances and Open Questions in the Science of Subjective Well-Being. Collabra. Psychol. 2018, 4, 15. [CrossRef] [PubMed]

7. Keyes, C.; Dhingra, S.; Simoes, E. Change in level of positive mental health as a predictor of future risk of mental illness. Am. J. Public Health 2010, 100, 2366. [CrossRef] [PubMed]

8. Slade, M. Mental illness and well-being: The central importance of positive psychology and recovery approaches. BMC Health Serv. Res. 2010, 10, 26. [CrossRef]

9. World Health Organization. Mental Health: Fact Sheet; World Health Organization: Geneva, Switzerland, 2019.

10. Grant, F.; Guille, C.; Sen, S. Well-being and the risk of depression under stress. PLoS ONE 2013, 8, e67395. [CrossRef]

11. Watson, D.; Naragon-Gainey, K. On the specificity of positive emotional dysfunction in psychopathology: Evidence from the mood and anxiety disorders and schizophrenia/schizotypy. Clin. Psychol. Rev. 2010, 30, 839-848. [CrossRef]

12. World Health Organization. Depression and Other Common Mental Disorders: Global Health Estimates; World Health Organization: Geneva, Switzerland, 2017.

13. Baker, G.; Gray, S.R.; Wright, A.; Fitzsimons, C.; Nimmo, M.; Lowry, R.; Mutrie, N. The effect of a pedometer-based community walking intervention "Walking for Wellbeing in the West" on physical activity levels and health outcomes: A 12-week randomized controlled trial. Int. J. Behav. Nutr. Phys. Act. 2008, 5, 44. [CrossRef] [PubMed]

14. Oswald, F.; Campbell, J.; Williamson, C.; Richards, J.; Kelly, P. A Scoping Review of the Relationship between Running and Mental Health. Int. J. Environ. Res. Public Health 2020, 17, 8059. [CrossRef]

15. Sport England. Active Lives Adult Data. Available online: https://activelives.sportengland.org/Home/AdultData (accessed on 11 April 2021).

16. Barton, J.; Pretty, J. What is the best dose of nature and green exercise for improving mental health-A multi-study analysis. Environ. Sci. Technol. 2010, 44, 3947-3955. [CrossRef] [PubMed]

17. Pretty, J.; Peacock, J.; Hine, R.; Sellens, M.; South, N.; Griffin, M. Green exercise in the UK countryside: Effects on health and psychological well-being, and implications for policy and planning. J. Environ. Plan. Manag. 2007, 50, 211-231. [CrossRef]

18. Thompson Coon, J.; Boddy, K.; Stein, K.; Whear, R.; Barton, J.; Depledge, M.H. Does participating in physical activity in outdoor natural environments have a greater effect on physical and mental wellbeing than physical activity indoors? A systematic review. Environ. Sci. Technol. 2011, 45, 1761. [CrossRef]

19. Biddle, S.; Mutrie, N.; Gorely, T. The Psychology of Physical Activity Determinants, Well-Being and Interventions, 3rd ed.; Routledge: London, UK, 2015.

20. Islam, M.M. Social Prescribing-An Effort to Apply a Common Knowledge: Impelling Forces and Challenges. Front. Public Health 2020, 8, 515469. [CrossRef]

21. Kilgarriff-Foster, A.; O'Cathain, A. Exploring the components and impact of social prescribing. J. Public Ment. Health 2015, 14, 127-134. [CrossRef]

22. Morris, T.; Roychowdhury, D. Physical activity for health and wellbeing: The role of motives for participation. Health Psychol. Rep. 2020, 8, 391-407. [CrossRef]

23. parkrun. Our Countries. Available online: https://www.parkrun.com/countries (accessed on 29 October 2021).

24. parkrun UK. Walking the Talk. Available online: https://blog.parkrun.com/uk/2020/04/20/walking-the-talk/ (accessed on 13 April 2020). 
25. parkrun Support. What Do the Volunteers Do? Available online: https://support.parkrun.com/hc/en-us/articles/200566523What-do-the-volunteers-do (accessed on 29 October 2021).

26. parkrun UK. A Look Back at 15 Years of parkrun. Available online: https://blog.parkrun.com/uk/2019/10/02/a-look-back-at15-years-of-parkrun/ (accessed on 22 February 2021).

27. Fleming, J. Parkrun: Increasing physical activity in primary care. Br. J. Gen. Pract. 2019, 69, 483-484. [CrossRef]

28. Stevinson, C.; Hickson, M. Exploring the public health potential of a mass community participation event. J. Public Health 2014, 36, 268-274. [CrossRef] [PubMed]

29. Hindley, D. "More Than Just a Run in the Park": An Exploration of Parkrun as a Shared Leisure Space. Leis. Sci. 2020, 42, 85-105. [CrossRef]

30. Rogerson, M.; Brown, D.K.; Sandercock, G.; Wooller, J.-J.; Barton, J. A comparison of four typical green exercise environments and prediction of psychological health outcomes. Perspect. Public Health 2016, 136, 171-180. [CrossRef]

31. Stevinson, C.; Hickson, M. Changes in physical activity, weight and wellbeing outcomes among attendees of a weekly mass participation event: A prospective 12-month study. J. Public Health 2019, 41, 807. [CrossRef]

32. Grunseit, A.; Richards, J.; Merom, D. Running on a high: Parkrun and personal well-being. BMC Public Health 2017, 18, 59. [CrossRef]

33. Shah, N.; Cader, M.; Andrews, W.P.; Wijesekera, D.; Stewart-Brown, S.L. Responsiveness of the Short Warwick Edinburgh Mental Well-Being Scale (SWEMWBS): Evaluation a clinical sample. Health Qual. Life Outcomes 2018, 16, 239. [CrossRef] [PubMed]

34. Eysenbach, G. Improving the quality of Web surveys: The Checklist for Reporting Results of Internet E-Surveys (CHERRIES). J. Med. Internet Res. 2004, 6, e34. [CrossRef] [PubMed]

35. Haake, S.; Bullas, A.; Quirk, H. parkrun Health and Wellbeing Survey 2018: UK. Available online: https://awrcparkrunresearch. files.wordpress.com/2020/05/uk-health-and-wellbeing-survey-v5.1-final.pdf (accessed on 2 October 2021).

36. Quirk, H.; Bullas, A.; Haake, S.; Goyder, E.; Graney, M.; Wellington, C.; Copeland, R.; Reece, L.; Stevinson, C. Exploring the benefits of participation in community-based running and walking events: A cross-sectional survey of parkrun participants. BMC Public Health 2021, 21, 1978. [CrossRef]

37. Stewart-Brown, S.; Platt, S.; Tennant, R.; Tennant, A.; Parkinson, J.; Weich, S. Internal construct validity of the Warwick-Edinburgh Mental Well-being Scale (WEMWBS): A Rasch analysis using data from the Scottish Health Education Population Survey. Health Qual. Life Outcomes 2009, 7, 15. [CrossRef]

38. Pescheny, J.V.; Gunn, L.H.; Pappas, Y.; Randhawa, G. The impact of the Luton social prescribing programme on mental well-being: A quantitative before-and-after study. J. Public Health (Oxf. Engl.) 2021, 43, e69-e76. [CrossRef]

39. Vaingankar, J.A.; Abdin, E.; Chong, S.A.; Sambasivam, R.; Seow, E.; Jeyagurunathan, A.; Picco, L.; Stewart-Brown, S.; Subramaniam, M. Psychometric properties of the short Warwick Edinburgh mental well-being scale (SWEMWBS) in service users with schizophrenia, depression and anxiety spectrum disorders. Health Qual. Life Outcomes 2017, 15, 153. [CrossRef]

40. Cohen, J. Statistical Power Analysis for the Behavioral Sciences, 2nd ed.; L. Erlbaum Associates: Hillsdale, NJ, USA, 1988.

41. Field, A.P. Discovering Statistics Using IBM SPSS Statistics, 5th ed.; SAGE: Los Angeles, CA, USA, 2018.

42. Ng Fat, L.; Scholes, S.; Boniface, S.; Mindell, J.; Stewart-Brown, S. Evaluating and establishing national norms for mental wellbeing using the short Warwick-Edinburgh Mental Well-being Scale (SWEMWBS): Findings from the Health Survey for England. Qual. Life Res. 2017, 26, 1129-1144. [CrossRef]

43. Warwick Medical School. Collect, Score, Analyse and Interpret WEMWBS. Available online: https://warwick.ac.uk/fac/sci/ med/research/platform/wemwbs/using/howto/ (accessed on 22 February 2021).

44. De Hert, M.; Correll, C.U.; Bobes, J.; Cetkovich-Bakmas, M.; Cohen, D.; Asai, I.; Detraux, J.; Gautam, S.; Moeller, H.-J.; Ndetei, D.M.; et al. Physical illness in patients with severe mental disorders. I. Prevalence, impact of medications and disparities in health care. World Psychiatry 2011, 10, 52-77. [CrossRef] [PubMed]

45. Vancampfort, D.; Correll, C.U.; Galling, B.; Probst, M.; De Hert, M.; Ward, P.B.; Rosenbaum, S.; Gaughran, F.; Lally, J.; Stubbs, B. Diabetes mellitus in people with schizophrenia, bipolar disorder and major depressive disorder: A systematic review and large scale meta-analysis. World Psychiatry 2016, 15, 166-174. [CrossRef] [PubMed]

46. Machaczek, K.; Allmark, P.; Goyder, E.; Grant, G.; Ricketts, T.; Pollard, N.; Booth, A.; Harrop, D.; De-La-Haye, S.; Collins, K.; et al. A scoping study of interventions to increase the uptake of physical activity (PA) amongst individuals with mild-to-moderate depression (MMD). BMC Public Health 2018, 18, 392. [CrossRef]

47. Baumann, A.E. Stigmatization, social distance and exclusion because of mental illness: The individual with mental illness as a 'stranger'. Int. Rev. Psychiatry (Abingdon Engl.) 2007, 19, 131-135. [CrossRef] [PubMed]

48. Morris, P.; Scott, H. Not just a run in the park: A qualitative exploration of parkrun and mental health. Adv. Ment. Health 2019, 17, 110-123. [CrossRef]

49. World Health Organization. Measurement of and Target-Setting for Wellbeing: An Initiative by the WHO Regional Office for Europe. Available online: https:/ / www.euro.who.int/_data/assets/pdf_file/0009/181449/e96732.pdf (accessed on 2 October 2021).

50. Quirk, H.; Haake, S. How can we get more people with long-term health conditions involved in parkrun? A qualitative study evaluating parkrun's PROVE project. BMC Sports Sci. Med. Rehabil. 2019, 11, 22. [CrossRef] [PubMed]

51. Fleming, J.; Bryce, C.; Parsons, J.; Wellington, C.; Dale, J. Engagement with and delivery of the 'parkrun practice initiative' in general practice: A mixed methods study. Br. J. Gen. Pract. 2020, 70, e573-e580. [CrossRef] [PubMed]

52. Stevinson, C.; Wiltshire, G.; Hickson, M. Facilitating Participation in Health-Enhancing Physical Activity: A Qualitative Study of parkrun. Int. J. Behav. Med. 2015, 22, 170-177. [CrossRef] [PubMed] 